\title{
Biological Tools to Deal with Pollution: Selected Advances and Novel Perspectives
}

\author{
Abdelaziz GHANEMI ${ }^{1,2}$, Besma BOUBERTAKH ${ }^{3}$ \\ ${ }^{1}$ Key Laboratory of Animal Models and Human Disease Mechanisms, Kunming Institute of Zoology Chinese Academy \\ of Sciences Yunnan Province, China \\ ${ }^{2}$ University of Chinese Academy of Sciences, Beijing, China \\ ${ }^{3}$ State Key Laboratory of Natural Medicines, China Pharmaceutical University, China
}

\begin{tabular}{|c|c|}
\hline Article Info & ABSTRACT \\
\hline Article history: & \multirow{9}{*}{$\begin{array}{l}\text { Pollution represents a problem common to economy and public health. } \\
\text { Indeed, the public health, because of the divers' types of pollutions, is facing } \\
\text { divers challenges for which urgent solutions are required. The biology } \\
\text { provides approaches not only to deal with the pollution, but also to obtain } \\
\text { economic benefits. Some living organisms have particular metabolisms that } \\
\text { allow them to assimilate and metabolite the polluting agents and thus reduce } \\
\text { the impact they have on both environment and public health. On the other } \\
\text { hand, the metabolic properties of specific organisms make the polluting } \\
\text { elements raw materials to synthesize other elements that benefit economy } \\
\text { and that are non-toxic for the ecology and the biohealth. Yet, other options } \\
\text { such as the regulations and laws are required to improve the efficiency of } \\
\text { these approaches. }\end{array}$} \\
\hline Docoived Des 202012 & \\
\hline Received Dec 29, 2013 & \\
\hline Revised Jan 20, 2014 & \\
\hline Accepted Feb 26, 2014 & \\
\hline Keyword: & \\
\hline Biological tool & \\
\hline Pollution & \\
\hline Public health & \\
\hline
\end{tabular}

Copyright (C) 2014 Institute of Advanced Engineering and Science. All rights reserved.

\section{Corresponding Author:}

Abdelaziz GHANEMI,

Key Laboratory of Animal Models and Human Disease Mechanisms, Kunming Institute of Zoology Chinese Academy of Sciences, No.32 JiaochangDonglu, Kunming 650223, Yunnan Province, China. Email: ghanemiabdelaziz@hotmail.com.

\section{INTRODUCTION}

As a consequence of development in many fields, the modern societies worldwide are facing a variety of pollution related problems that result mainly in both environment [1]-[5] and public health deteriorations [6]-[12]. Indeed, pollutions, especially in big cities, due basically to the industrial activities, have negative effects on air quality [13],[14], soil [15],[16] water [17]-[20] and the divers existing life forms [21]-[23] that represent the biological entities of the ecosystems ,thus, vegetations, animals and humans are less likely to exist in a healthy state which can influence for example the crops of the agriculture and thus, the food security by influencing elements including the yields [24]-[26]. In addition the economic impacts of the pollution are also important and make reducing pollution crucial for the financial stability as well [27],[28]. All these parameters influence the quality of the life of citizens and the whole country development. Thus, solutions to deal with these phenomena are required as an urgent matter. However, these solutions should not stop or suspend the economic development of the country.

The best ways remains to make a balance between a sustainable technological development and a pollution control that would consider the sanitary aspects and the ecological issues; this would be possible through making efficient exploitations of the recent scientific and technological advanced tools within different facilities especially those with heavy impactson environment and human health. Herein, selected examples are presented to illustrate these concepts. 


\section{PRACTICAL SOLUTIONS}

Regarding the industrial installations, and depending on the wastes they produce $\left(\mathrm{CO}_{2}\right.$, organic products, mineral chemicals, etc), we should consider making use of biological advances [29], such as including bacterial cultures [30],[31], fungi cultures [32] or algae cultures [33] into specific compartments within the installations or in the natural environment such as agricultural soils. The wastes would be passed via these compartments to be clarified and purified. The clarification and purification principle is based on the properties of these cultures (bacterial, fungal and algal) to consume or assimilate elements that are included within the wastes [34] $\left(\mathrm{CO}_{2}\right.$, organic products or mineral chemicals) and incorporate them within their metabolism and this would help to avoid spreading these wastes in the rivers and the air for example. In addition, these biological organisms not only use the wastes in their metabolisms, but may also use them to produce elements that can be used in some industries [29], including fuel, pharmaceutical active compounds, elements used in food industry, etc, and as example, we mention lipid production [35] and metals accumulation by those organisms. This can be named as biological recycling of pollusting agents to reintegrate them either to the ecological system or to industrial processes.

On the other hand, nearby the exo-energetic industries (exothermic), which produce heat [36], we can install-plantations of plants or animals that are adapted to the hot climate such as deserts [37], which means we use the heat and the energy produced by certain installations to create an artificial environment that mimics zones like deserts and tropical areas, and thus, we could produce crops that need high temperatures and raise animals that live in the hot climate. More important, this approach could allow us to use the generated energy and heats instead of spreading it within the atmosphrere and contribute in increasing the global temperature. The application of these aspects would be beneficial not only for agriculture, animal husbandry, but also might have an improving effect on tourism through creating touristic scenic spots such as botanical gardens and zoological parks; however, it is vital to consider parallel the application of other possible purification methods to ensure the safest environment conditions. These methods that would reduce the polluting elements such as $\mathrm{CO}_{2}$, would also, since they are mainly based on the use of biological organisms, produce oxygen and reduce the heat released in the nature, which means that these methods would contribute in reducing the global warming [38]-[40].

Moreover, we can apply domestication methods, breeding and genetic modification techniques to improve these biological organisms' properties [41]-[43] through developing organisms with new traits that would be more likely to achieve the purposes we are seeking which means more efficient organisms with better properties.

Importantly, these proposed solutions have the advantages to provide economic outcome and financial benefits, which make them different form the classical methods such as filters [44],[45], which might be costly and with less benefits. Since these methods could be highly beneficial at several levels, they might, most probably, be successful and more likely to attract investments, particularly because they are economical and eco-friendly at the same time. Solving the problem of disposing industrial wastes is beneficially, not only by managing wastes and emissions, but also through considering them as raw materials for other sectors rather than just a problem to deal with. Indeed, these pollutants will become a resource to produce other elements that would be used, for instance in industry or agriculture.

Another option would be to put laboratory animals, microorganisms and plants nearby the industrial stations and installations, which are suspected to influence the bio-health and the ecological system, then it is suggested to study and investigate those living organisms transformations under this environmental and artificial circumstances during a period of time estimated via extrapolation form the exiting data and based on the plant or animal type and ability to resist. This could lead to obtain more precise and more accurate data about the impact those stations and installations have on living organisms. The investigations should be complete and include medical, toxicological, pathological hydrological [46] and other relevant biological and environmental required studies[47-50], in addition of collecting geological, climatologic and chemical data in order to come out with thorough investigations, eventual linkage and fruitful conclusions.

\section{IMPLICATIONS}

More general concepts emerge from the extrapolation of these approaches. Indeed, for each type of pollution or industrial wastes we may deal with, we should consider the appropriate scientific and technological methodologies that could allow us to use these wastes to produce new compounds for further industrial use for example or create new artificial environments to both study the pollution impact and a small level within a selected sample and make use of these artificial environments to produce biological entities such as agricultural crops.

Undoubtedly, methods and standard for pollution evaluation should be improved and optimized [21],[47],[51]-[60] although currently some many methods exist such as the use of divers organisms cultures 
as indicator of the pollution degree and the biological impact [61]-[63] some of them have limits and disadvantages.

Yet, the combination of knowledge form many fields and the common efforts of experts in different areas ,supported by efficient legislations [64]-[66], political willing and a scientific education of the citizens [67],[68] will make as going ahead toward realizing such projects for the benefits of all in order to achieve the best results.

\section{ACKNOWLEDGEMENTS}

Abdelaziz GHANEMI is the recipient of a 2013 CAS-TWAS President's Postgraduate Fellowship.

\section{REFERENCES}

[1] Majer, A.P., et al. "Bioaccumulation of potentially toxic trace elements in benthic organisms of Admiralty Bay (King George Island, Antarctica)", Mar Pollut Bull, 2013.

[2] Mailler, R., et al. "Biofiltration vs conventional activated sludge plants: what about priority and emerging pollutants removal?", Environ Sci Pollut Res Int, 2013.

[3] Ettler, V., et al. "Surprisingly contrasting metal distribution and fractionation patterns in copper smelter-affected tropical soils in forested and grassland areas (Mufulira, Zambian Copperbelt), Sci Total Environ, Vol. 473-474C. Pp. 117-124, 2013.

[4]. Vallius, H. "Heavy metal concentrations in sediment cores from the northern Baltic Sea: Declines over the last two decades", Mar Pollut Bull, 2013.

[5] Nie, M., et al. "Environmental estrogens in a drinking water reservoir area in Shanghai: Occurrence, colloidal contribution and risk assessment", Sci Total Environ, 2013.

[6] Smith, E., et al. "Influence of in vitro assay pH and extractant composition on As bioaccessibility in contaminated soils", Sci Total Environ, Vol. 473-474C. Pp. 171-177, 2013.

[7] Liu, Y., et al. "Concentrations and safety evaluation of heavy metals in aquatic products of Yancheng, Jiangsu Province", Huan Jing Ke Xue, Vol/Issue: 34(10). Pp. 4081-9, 2013.

[8] Sun, R.X., et al. "Residues and risk assessment of polycyclic aromatic hydrocarbons in the surface sediments and marine organisms from Dapeng Bay, Shenzhen", Huan Jing Ke Xue, Vol/Issue: 34(10). Pp. 3832-9, 2013.

[9] Drummond, M.B. "Obstructive airway disease in urban populations", Curr Opin Pulm Med, 2013.

[10] Burkart, K., et al. "Interactive short-term effects of equivalent temperature and air pollution on human mortality in Berlin and Lisbon", Environmental Pollution, Vol. 183(0). Pp. 54-63, 2013.

[11] Barakat-Haddad, C., S.J. Elliott, and D. Pengelly. "Health Impacts of Air Pollution: A Life Course Approach for Examining Predictors of Respiratory Health in Adulthood", Annals of Epidemiology, Vol/Issue: 22(4). Pp. 239249, 2012.

[12] Huang, Z., et al. "Heavy metals in vegetables and the health risk to population in Zhejiang, China", Food Control, Vol/Issue: 36(1). Pp. 248-252, 2014.

[13] Tao, Y., et al. "Air pollution and hospital admissions for respiratory diseases in Lanzhou, China", Environmental Pollution, Vol. 185(0). Pp. 196-201, 2014.

[14] Zhou, M., et al. "Particulate air pollution and mortality in a cohort of Chinese men", Environmental Pollution, Vol. 186(0). Pp. 1-6, 2014.

[15] Li, Z., et al. "A review of soil heavy metal pollution from mines in China: Pollution and health risk assessment, Science of The Total Environment, Vol. 468-469(0). Pp. 843-853, 2014.

[16] Li, W., et al. "The identification of 'hotspots' of heavy metal pollution in soil-rice systems at a regional scale in eastern China", Science of The Total Environment, Vol. 472(0). Pp. 407-420, 2014.

[17] Mahmoud, I.Y., S.N. Al-Bahry, and S.K. Al-Musharafi. "Fresh Water Habitat Pollution by Treated Sewage Effluent in Relation to Multiple-Antibiotic-Resistant Bacteria", APCBEE Procedia, Vol. 5(0). Pp. 363-367, 2013.

[18] Ahuja, S. 1 - Monitoring Water Quality, Pollution Assessment, and Remediation to Assure Sustainability, in Monitoring Water Quality, S. Ahuja, Editor. Amsterdam: Elsevier. Pp. 1-18, 2013.

[19] Vasudha Bhandari, P.A. "Field Monitoring of Treated Industrial Waste Water", International Journal of Electrical and Computer Engineering, Vol/Issue: 3(5). Pp. 6, 2013.

[20] Agung Warsito, A.S., Syafrudin, Galuh Susilowati. "An Ozone Reactor Design with Various Electrode Configurations", International Journal of Electrical and Computer Engineering, Vol/Issue: 1(2). Pp. 8, 2011.

[21] Torres, M.A., et al. "Biochemical biomarkers in algae and marine pollution: A review", Ecotoxicology and Environmental Safety, Vol/Issue: 71(1). Pp. 1-15, 2008.

[22] Lewis, M. and R. Pryor. "Toxicities of oils, dispersants and dispersed oils to algae and aquatic plants: Review and database value to resource sustainability", Environmental Pollution, Vol. 180(0). Pp. 345-367, 2013.

[23] Pokora, W., et al. "Adaptation strategies of two closely related Desmodesmus armatus (green alga) strains contained different amounts of cadmium: A study with light-induced synchronized cultures of algae", Journal of Plant Physiology, Vol/Issue: 171(2). Pp. 69-77, 2014.

[24] Tacarindua, C.R.P., et al. "The effects of increased temperature on crop growth and yield of soybean grown in a temperature gradient chamber", Field Crops Research, Vol. 154(0). Pp. 74-81, 2013.

[25] Schulte, L.R., et al. "Increased growing temperature reduces content of polyunsaturated fatty acids in four oilseed crops", Industrial Crops and Products, Vol. 51(0). Pp. 212-219, 2013.

Biological Tools To Deal With Pollution: Selected Advances and Novel Prespectives (Abdelaziz Ghanemi) 
[26] Wei, J., et al. "Industrial SO2 pollution and agricultural losses in China: evidence from heavy air polluters", Journal of Cleaner Production, Vol. 64(0). Pp. 404-413, 2014.

[27] Ambrey, C.L., C.M. Fleming, and A.Y.-C. Chan. "Estimating the cost of air pollution in South East Queensland: An application of the life satisfaction non-market valuation approach", Ecological Economics, Vol. 97(0). Pp. 172181, 2014.

[28] Biswas, A.K., M.R. Farzanegan, and M. Thum. "Pollution, shadow economy and corruption: Theory and evidence", Ecological Economics, Vol. 75(0). Pp. 114-125, 2012.

[29] Liu, W., et al. "Engineering of the xylose metabolic pathway for microbial production of bio-based chemicals", Sheng Wu Gong Cheng Xue Bao, Vol/Issue: 29(8). Pp. 1161-72, 2013.

[30] Othman, A.R., et al. "Kinetics of Molybdenum Reduction to Molybdenum Blue by Bacillus sp", Strain A.rzi. Biomed Res Int, Pp. 371058, 2013.

[31] Chang, J.J., et al. "Characteristics and functional protein analysis of an effective decabromodiphenyl etherdegrading strain", Huan Jing Ke Xue, Vol/Issue: 34(10). Pp. 4112-8, 2013.

[32] Nguyen, L.N., et al. "Removal of trace organic contaminants by an MBR comprising a mixed culture of bacteria and white-rot fungi", Bioresource Technology, Vol. 148(0). Pp. 234-241, 2013.

[33] Zhang, J., D. Fu, and J. Wu. "Photodegradation of Norfloxacin in aqueous solution containing algae", Journal of Environmental Sciences, Vol/Issue: 24(4). Pp. 743-749, 2012.

[34] Li, W.Y., et al. "Wastewater pollution characteristics from typical intensive pig farms in the Pearl River Delta and its ecological risk assessment", Huan Jing Ke Xue, Vol/Issue: 34(10). Pp. 3963-8, 2013.

[35] Riedel, S.L., et al. "Lipid and fatty acid metabolism in Ralstonia eutropha: relevance for the biotechnological production of value-added products", Appl Microbiol Biotechnol, 2013.

[36] Karellas, S., et al. "Energetic and exergetic analysis of waste heat recovery systems in the cement industry", Energy, Vol. 58(0). Pp. 147-156, 2013.

[37] Aldossary, N.A., Y. Rezgui, and A. Kwan. "Domestic energy consumption patterns in a hot and arid climate: A multiple-case study analysis", Renewable Energy, Vol. 62(0). Pp. 369-378, 2014.

[38] Lee, Z.H., et al. "An overview on global warming in Southeast Asia: CO2 emission status, efforts done, and barriers", Renewable and Sustainable Energy Reviews, Vol. 28(0). Pp. 71-81, 2013.

[39] Radhi, H. "Evaluating the potential impact of global warming on the UAE residential buildings - A contribution to reduce the CO2 emissions", Building and Environment, Vol/Issue: 44(12). Pp. 2451-2462, 2009.

[40] de_Richter, R.K., T. Ming, and S. Caillol. "Fighting global warming by photocatalytic reduction of CO2 using giant photocatalytic reactors", Renewable and Sustainable Energy Reviews, Vol. 19(0). Pp. 82-106, 2013.

[41] Hill, W.G. Selective Breeding, in Brenner's Encyclopedia of Genetics (Second Edition), S. Maloy and K. Hughes, Editors, San Diego: Academic Press. Pp. 371-373, 2013.

[42] Goldman, I.L. Biodiversity in Plant Breeding, in Encyclopedia of Biodiversity (Second Edition), S.A. Levin, Editor. Waltham: Academic Press. Pp. 459-469, 2013.

[43] De La Fuente, G.N., U.K. Frei, and T. Lübberstedt. "Accelerating plant breeding", Trends in Plant Science, Vol/Issue: 18(12). Pp. 667-672, 2013.

[44] San-Valero, P., et al. "Study of Mass Oxygen Transfer in a Biotrickling Filter for Air Pollution Control", Procedia Engineering, Vol. 42(0). Pp. 1726-1730, 2012.

[45] Kuo, Y.M. and R. Muñoz-Carpena. "Simplified modeling of phosphorus removal by vegetative filter strips to control runoff pollution from phosphate mining areas", Journal of Hydrology, Vol/Issue: 378(3-4). Pp. 343-354, 2009.

[46] Macikova, P., et al. "Longer-term and short-term variability in pollution of fluvial sediments by dioxin-like and endocrine disruptive compounds", Environ Sci Pollut Res Int, 2013.

[47] Sánez, J., S. Froehner, and F. Falcão. "Use of biomarkers indices in a sediment core to evaluate potential pollution sources in a subtropical reservoir in Brazil", Chemie der Erde - Geochemistry, Vol/Issue: 73(4). Pp. 555-563, 2013.

[48] Saeed, A. and I. Hashmi. "Evaluation of anthropogenic effects on water quality and bacterial diversity in Rawal Lake, Islamabad", Environ Monit Assess, 2013.

[49] Li, G.X. and X.C. Pan. "Evaluation of excess mortality caused by PM2.5 in four typical Chinese big cities", Zhonghua Yi Xue Za Zhi, Vol/Issue: 93(34). Pp. 2703-6, 2013.

[50] Araújo, S., et al. "Gulls identified as major source of fecal pollution in coastal waters: A microbial source tracking study", Science of The Total Environment, Vol. 470-471(0). Pp. 84-91, 2014.

[51] Bian, L., T. Li, and J. Hou. "Source apportionment of polycyclic aromatic hydrocarbons using two mathematical models for runoff of the Shanghai elevated inner highway, China", Huan Jing Ke Xue, Vol/Issue: 34(10). Pp. 38406, 2013.

[52] Li, H.Y., et al. "Fractal characteristics of capillary finger flow for NAPLs infiltrated in porous media", Huan Jing Ke Xue, Vol/Issue: 34(10). Pp. 4058-65, 2013.

[53] Wu, Y.Y., et al. "Vertical distribution of polycyclic aromatic hydrocarbons in abandoned vehicles dismantling area soil", Huan Jing Ke Xue, Vol/Issue: 34(10). Pp. 4031-5, 2013.

[54] Shi, S.X., et al. "Polybrominated diphenyl ethers and polychlorinated biphenyls in road dust from Suzhou, Wuxi and Nantong", Huan Jing Ke Xue, Vol/Issue: 34(10). Pp. 4024-30, 2013.

[55] Yan, H., J. Chen, and J. Xiao. "Heavy metal content in street dust and environmental risk assessment of agricultural city: A case study of Xuchang City", Huan Jing Ke Xue, Vol/Issue: 34(10). Pp. 4017-23, 2013.

[56] Li, F.P., H.P. Zhang, and L. Chen. "Temporal and spatial distribution of environmental factors and chlorophyll-a and their correlation analysis in a small enclosed lake", Huan Jing Ke Xue, Vol/Issue: 34(10). Pp. 3854-61, 2013. 
[57] Nie, H.F., et al. "Analysis of ecological risk and the content situation of polybrominated diphenyl ethers in sediments from Northeast China River Basin", Huan Jing Ke Xue, Vol/Issue: 34(10). Pp. 3825-31, 2013.

[58] Wang, X.L., et al. "Research on spatial characteristic of non-point source pollution in Liaohe River basin", Huan Jing Ke Xue, Vol/Issue: 34(10). Pp. 3788-96, 2013.

[59] Wu, M.L., et al. "Stable carbon isotopic composition in PM 2.1 in Nanjing Region", Huan Jing Ke Xue, Vol/Issue: 34(10). Pp. 3727-32, 2013.

[60] Wang, Z., et al. "Combined use of DGT and transplanted shrimp (Litopenaeus vannamei) to assess the bioavailable metals of complex contamination: implications for implementing bioavailability-based water quality criteria", Environ Sci Pollut Res Int, 2013.

[61] Dokulil, M.T. "Chapter 9 Algae as ecological bio-indicators, in Trace Metals and other Contaminants in the Environment", A.M.B. B.A. Markert and H.G. Zechmeister, Editors, Elsevier. Pp. 285-327, 2003.

[62] Yu, X., et al. "Toxicity evaluation of pharmaceutical wastewaters using the alga Scenedesmus obliquus and the bacterium Vibrio fischeri", Journal of Hazardous Materials, Vol. 266(0). Pp. 68-74, 2014.

[63] Edwards, P. "Cultured red alga to measure pollution", Marine Pollution Bulletin, Vol/Issue: 3(12). Pp. 184-188, 1972.

[64] Schoenberger, H. "Integrated pollution prevention and control in large industrial installations on the basis of best available techniques - The Sevilla Process", Journal of Cleaner Production, Vol/Issue: 17(16). Pp. 1526-1529, 2009.

[65] Mannan, S. Chapter 3 - Legislation, Law, and Standards, in Lees' Process Safety Essentials, S. Mannan, Editor, Oxford: Butterworth-Heinemann. Pp. 31-39, 2014.

[66] Zeng, X., et al. "Perspective of electronic waste management in China based on a legislation comparison between China and the EU", Journal of Cleaner Production, Vol. 51(0). Pp. 80-87, 2013.

[67] Barbat, A.C., et al. "Residents' Perceptions of Coal Industry Long-Term Pollution in the Jiu Middle Valley (Romania): Premise for Environmental Education", Procedia - Social and Behavioral Sciences, Vol. 46(0). Pp. 870-874, 2012.

[68] Hine, D.W., et al. "Comparing the effectiveness of education and technology in reducing wood smoke pollution: A field experiment", Journal of Environmental Psychology, Vol/Issue: 31(4). Pp. 282-288, 2011.

\section{BIOGRAPHY OF AUTHOR}

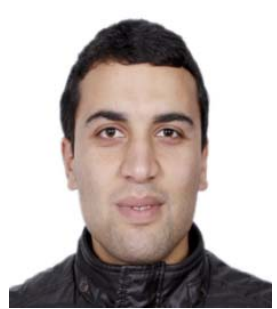

Abdelaziz GHANEMI was born on October, $11^{\text {th }}, 1986$ in Algiers (Algeria). He finished his elementary and high school education in Constantine (Algeria). In 2004, he graduated from Houari Boumédiène High School with the Secondary Education Baccalaureate Degree with honors (Good). In 2009, Abdelaziz GHANEMI graduated from the Medicine Faculty of Mentouri Constantine University (Algeria) with a Pharmacist Diploma (Valedictorian). From September 2009 to June 2010: Chinese language Class at China Pharmaceutical University (Nanjing city, Jiangsu Provence, China). From September 2010 to June 2013: Master’s degree (Msc) in Pharmacology at China Pharmaceutical University (China). In addition to Arabic (mother tongue), Mr.GHANEMI has English, French and Chinese language proficiency certificates. The author does research and has publications about both pharmacology and neuroscience-related fields. 